\title{
Measurement of High-Resolution Recrystallization Textures in Nickel Sheets using High-Energy Synchrotron Radiation
}

\author{
H.Klein ${ }^{a)}$, A.Preusser ${ }^{(b)}$, H.J.Bunge ${ }^{b)}$, L, Raue ${ }^{a)}$ and J.R.Schneider ${ }^{()}$. \\ a) Department of Crystallography, University of Göttingen, Goldschmidtstr. 1, D-37077 Göttingen, Department \\ of Physics and Physical Technologies, Technical University of Clausthal, Leibnizstr. 4, D-38678 Clausthal- \\ Zellerfeld, Germany; Germany; ${ }^{c)} H A S Y L A B$ at DESY, Notkestr. 85, D-22603 Hamburg, Germany.
}

The basic processes of microstructure formation, e.g. plastic deformation, nucleation, and grain boundary movement are anisotropic. They depend on the crystallographic orientation of a considered grain as well as on the orientations of its neighbours with which it interacts. Hence, plastic deformation and recrystallization both give rise to the formation of textures, some of which have achieved considerable technological interest. The classical texture i.e. the orientation distribution function (ODF) of the crystallites does not distinguish individual grains, i.e. their sizes, shape and arrangement in the polycrystalline aggregate [1]. Hence, the classical texture is not sufficient in order to understand the formation mechanism of recrystallization textures, particularly the difficult interaction processes during dynamic recrystallization.

In order to understand these processes it is necessary to know the complete orientation stereology as well as its changes with the time during recrystallization. The orientation stereology can be measured with the technique of orientation imaging microscopy [2,3]. This technique is well established and automated in the reflection scanning electron microscope. It yields, however, only a two-dimensional section of the function $\mathbf{g}(\mathbf{x})$ at the sample surface which has also been called orientation topology. It is not suited to measure the kinetics $\mathbf{g}(\mathbf{x}, \mathbf{t})$ of the three-dimensional function during recrystallization processes, particularly not in the interior of the material.

The six-dimensional orientation-location space must be imaged with the highest possible orientation- and location resolution. This can be done by location-resolved diffraction of highenergy synchrotron radiation $[4,5,6]$. In order to fully exploit the high resolving power of this radiation, the conventional step-scan technique had to be replaced by a continuous "sweeping" technique with a moving detector [5,6,7].

For this purpose either a diffraction angle slit or a diffraction plane slit was introduced additionally between sample and detector in the diffractometer at the high-energy beam-line BW5 at HASYLAB [6,7]. During exposure the detector is being shifted continuously while, at the same time, the sample is being rotated or translated, continuously, too. This technique allows to measure different types of two-dimensional images which are sections and projections of the sixdimensional orientation-location space $[5,6,7]$.
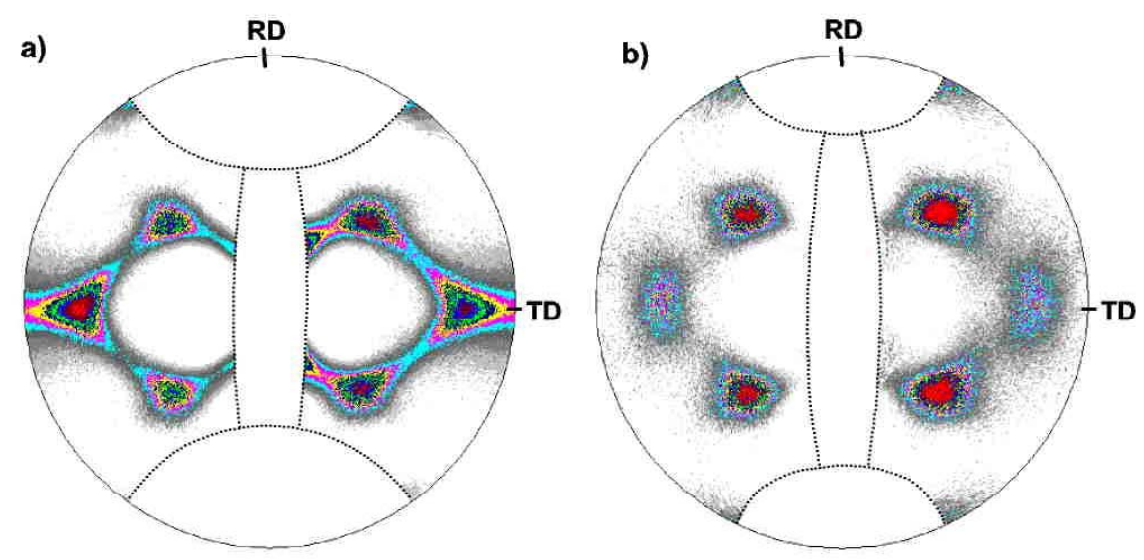

Fig.1 High Resolution (111) pole figures of cold rolled $\mathrm{Ni}$ sheet annealed a) $45 \mathrm{~min}$ and b) $300 \mathrm{~min}$ at $600^{\circ} \mathrm{C}$ (Note the „blind“areas which are not seen in this technique). 
The different methods were used to study orientation and local distributions of crystallites in recrystallized $\mathrm{Ni}$ sheets and hot rolled and subsequently annealed Al-alloy samples [8]. As an example Fig. 1 shows high-resolution pole figures of a cold rolled and subsequently recrystallized Ni-sheet.

Another example is the measurement of location scans (method b), fig.2 shows the (111) reflections of a $30 \mathrm{~min}$ and a $45 \mathrm{~min}$ annealed Ni sample $\left(\omega=0^{\circ}\right)$. In these scans a crystallite is imaged by a streak rather then a point. The streak length corresponds to the grain diameter in scanning direction. Beside the streaks continuous intensity can also be seen. These areas may be attributed to deformed material which is not yet recrystallized.

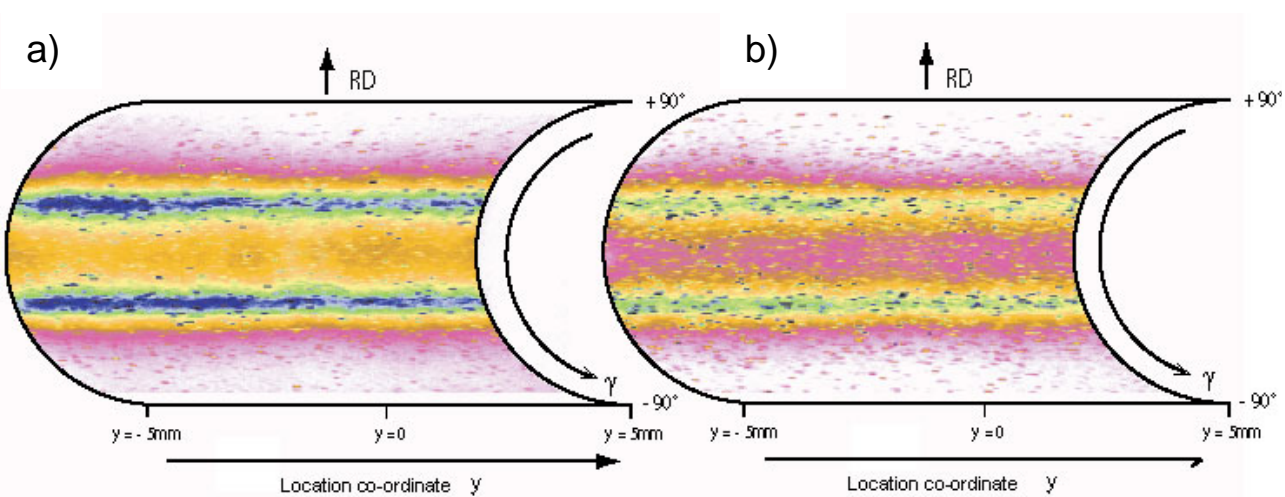

Fig.2 Location resolved scans of a recrystallized $\mathrm{Ni}$ sheet in (111) reflection. Scanning length was 10mm. Annealing times: a) $30 \mathrm{~min}$, b) $45 \mathrm{~min}$.

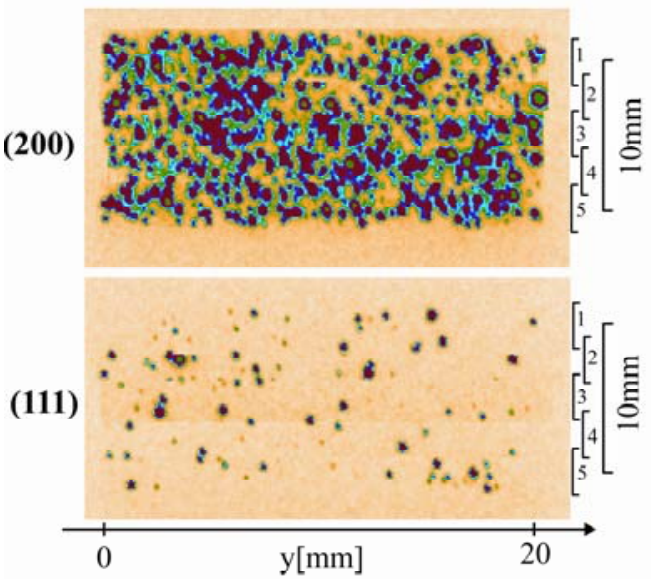

Fig. 3 shows the projected cross-sections of grains with selected orientations of a fully recrystallized nickel sheet. The grains correspond to one particular diffraction vector in each of the two partial diagrams i.e. they are near to the main texture component and far away from it, respectively. With this technique the development of individual grains during recrystallization and continuous grain coarsening can be very well studied.

Fig. 3 Location scan at $\omega^{\circ}=0^{\circ}$ of the $300 \mathrm{~min}$ at $600^{\circ} \mathrm{C}$ recrystallized $\mathrm{Ni}$-sheet in the (200) and (111) reflection.

\section{References}

[1] H.J. Bunge. Texture Analysis in Material Science. Butterworth Publ. London, 1982.

[2] B.L. Adams, D.J. Dingley, K. Kunze, S.I. Wright. Orientation Imaging Microscopy: New Possibilities for Microstructural Investigations Using Automated BKD Analysis. Proc. ICOTOM-10, Material Science Forum 157-162 (1994) 31-42.

[3] H.J. Bunge, R.A. Schwarzer. Orientation Stereology-A new Branch in Texture Research. Adv. Eng. Mater. 3 (2001) 25-39

[4] L. Wcislak, H. Klein, H.J. Bunge, U. Garbe, T. Tschentscher and J.R. Schneider. Texture Analysis with High-Energy Synchrotron Radiation. J. Appl. Cryst. 35 (2002) 82-95.

[5] H.J. Bunge, L. Wcislak, H. Klein, U. Garbe and J.R. Schneider. Orientation Imaging of Crystals in Polycrystalline Materials. Adv. Eng. Mater. 4 (2002) 300-305.

[6] H.J. Bunge, L. Wcislak, H. Klein, U. Garbe and J.R. Schneider. Texture and Microstructure Imaging in Six Dimensions with High-Energy Synchrotron Radiation. J. Appl. Cryst. 36 (2003) 1240-1255.

[7] H.J. Bunge, H. Klein, L. Wcislak, U. Garbe, W. Weiß and J.R. Schneider. High Resolution Imaging of Textures and Microstructure by the Moving Detector Method. Textures and Microstructures 35 (2003) 253-271.

[8] H. Klein, A. Preusser, H.J. Bunge and L. Raue. Proc. of 2. Int. Conf. on Recrystallization and Grain Growth, Material Science Forum, Vols.467-470 (2004) 1379-1384. 